\section{P29 IS WORKFORCE PARTICIPATION DETRIMENTAL TO THE MENTAL HEALTH OF WOMEN AND CHILDREN? EVIDENCE FROM SIX WAVES OF DATA FROM THE LONGITUDINAL STUDY OF AUSTRALIAN CHILDREN}

${ }^{1} \mathrm{TL}$ King ${ }^{*},{ }^{1} \mathrm{M}$ Shields, ${ }^{1} \mathrm{~S}$ Byars, ${ }^{2} \mathrm{~L}$ Craig, ${ }^{1} \mathrm{~A}$ Milner. ${ }^{1}$ Centre for Health Equity, Melbourne School of Population and Global Health, The University of Melbourne, Carlton, Australia; ${ }^{2}$ School of Social and Political Sciences, The University of Melbourne, Carlton, Australia

\subsection{6/jech-2019-SSMabstracts. 180}

Background The past 50 years has been marked by the increasing participation of women in the workforce. There is some evidence that this expansion of women into the workforce may impose a mental health burden on women, and it is popularly speculated that children are also adversely affected. This analysis aimed to examine the associations between household workforce participation (household employment configuration) on the mental health of mothers and children

Methods Six waves of data from the Longitudinal Study of Australian Children were used, from 2004 (when children were aged 4-5 years) to 2014 (age 14-15 years). Mental health outcome measures were the Strengths and Difficulties Questionnaire scores for children and adolescents, and the Kessler-6 score for mothers. A five-category measure of household employment configuration was derived from parent report (dual full time; male breadwinner; female breadwinner; shared employment (both part-time); father full time/mother part time). Mundlak models were used to compare withinand between-person effects after controlling for confounders including mother's country of birth; mother's indigenous status; mother's education; mother's occupation; area disadvantage; household income; mother's age; number of children in household; presence of child under 5 years; maternal mental health (in child models); and child mental health (in maternal models). Models were restricted to those households in which household employment configuration changed, with the reference category being the father full time/mother part time configuration.

Results There were no within-person effects of employment configuration on maternal mental health, however betweenperson effects indicated that women in a male breadwinner household had poorer mental health than women in a father full time/mother part time household (B 0.63, 95\%CI 0.021.24). There were no between- or within-person effects for children/adolescents.

Conclusion These results counter prevailing social attitudes regarding women's workforce participation by demonstrating that children are not adversely affected by their mother's workforce participation, nor are they disadvantaged by the extent of this participation. Also contrary to normative social expectations, women in traditional 'male breadwinner' household configurations experience poorer mental health than those in a 'father full-time/mother part-time' arrangement. Importantly too, no adverse mental health effects were observed in women working full time, either as a breadwinner or in a dual full-time arrangement (where both partners work full time). These results are important in demonstrating that increasing women's workforce participation is not detrimental to the mental health of either themselves, nor their children.

\section{P30 \\ UNINTENTIONAL INJURY IN ENGLAND: AN ANALYSIS OF THE EMERGENCY CARE DATA SET PILOT IN OXFORDSHIRE FROM 2012 TO 2014}

${ }^{1} \mathrm{G}$ Kirkwood*, ${ }^{2} \mathrm{TC}$ Hughes, ${ }^{1} \mathrm{AM}$ Pollock. ${ }^{1}$ Institute of Health and Society, Newcastle University, Newcastle, UK; ${ }^{2}$ Oxford University Hospitals NHS Foundation Trust, Oxford, UK

\subsection{6/jech-2019-SSMabstracts.181}

Background Unintentional injuries are a major cause of morbidity and mortality worldwide. The incidence of unintentional injury and death from unintentional injury are associated with higher levels of area-level socioeconomic deprivation in the UK. The UK is one of the few developed nations in the world without a national injury data collection system or database. A pilot injury data collection exercise at the emergency departments of Oxford University Hospitals National Health Service (NHS) Foundation Trust (OUH) ran from 2012 to 2014 to inform the current development of the new NHS England emergency care data set.

Methods Data collected at the two emergency departments of Oxford University Hospitals NHS Foundation Trust from 01 January 2012 to 30 March 2014 were analysed for Oxford City and Cherwell District Council areas.

Results Of the 63877 injury attendances recorded at the two sites, 26536 were unintentional with a home postcode within Oxford City or Cherwell District Council areas. The most frequent location, mechanism, activity and diagnosis were home (39.1\% of all unintentional injuries), low-level falls (47.1\%), leisure (31.1\%) and injuries to unspecified part of trunk, limb or body region' (20.5\%), respectively. The most deprived quintile of the population (Index of Multiple Deprivation (IMD) 1) had the highest European Age Standardised Rate (EASR) for all unintentional injuries and IMD 5 had the lowest, 54.4 (95\% CI 52.3 to 56.5 ) and 32.2 (31.4 to 33.0) per 1000 person years, respectively. There was a significant association between increasing levels of deprivation and an increasing incidence rate ratio (IRR) for all unintentional injuries, for those in the home, for low-level fall unintentional injuries and for non-sport leisure unintentional injuries with a particularly sharp increase in the IRR for IMD 1 compared with IMD 5. Sport-related injuries were inversely related to deprivation apart from football.

Conclusion This pilot has demonstrated both the feasibility and importance of prioritising the collection of a national injury data set.

\section{P31 ABDOMINAL OBESITY AND PROSTATE CANCER RISK: RESULTS FROM THE EPICAP STUDY}

${ }^{1} \mathrm{C}$ Lavalette ${ }^{*},{ }^{1} \mathrm{E}$ Cordina Duverger, ${ }^{1} \mathrm{~S}$ Cénée, ${ }^{2} \mathrm{X}$ Rebillard, ${ }^{2,3} \mathrm{PJ}$ Lamy, ${ }^{4} \mathrm{~B}$ Trétarre, ${ }^{1} \mathrm{~F}$ Menegaux. ${ }^{1}$ CESP Team Cancer and Environment, Université Paris-Saclay, Université Paris-Sud, Inserm, Villejuif, France; '2Service Urologie, Clinique Beau Soleil, Montpellier, France; Institut médical d'Analyse Génomique-Imagenome, Labosud, Montpellier, France; ${ }^{4}$ Registre des Tumeurs de I'Hérault, EA 2415, ICM, Montpellier, France

\subsection{6/jech-2019-SSMabstracts. 182}

Background Obesity is associated with an increased risk of several cancers, but the relationship between obesity and prostate cancer ( $\mathrm{PCa}$ ) remains controversial. We showed than body mass index (BMI) itself is not associated with $\mathrm{PCa}$, while central obesity indicators, such as waist circumference (WC) or 
waist-hip ratio (WHR), were associated with increased risks of $\mathrm{PCa}$. To further explore this relationship and given the accumulating evidence between BMI and smoking in cancer risk, we conducted further analyses taking into account smoking status within the EPICAP study.

Methods EPICAP is a French population-based case-control study that enrolled 819 incident cases of PCa diagnosed in 2012 and 2013, aged less than 75 years old and residing in the département of Hérault, France. Controls were 879 agematched individuals living in the same geographic area. Face to face interviews, using a standardized computerized questionnaire, gathered information about socio-demographic characteristics, personal medical history, lifestyle factors, physical activity, residential and occupational history. Anthropometric indicators have also been collected through the questionnaire (self-report of height at 18 years old and weight every decades) or anthropometric measures at time of interview (height, weight, waist and hip circumferences). Logistic regression models were used to assess odds ratios (ORs) for the associations between anthropometric indicators (BMI, WC, WHR) and $\mathrm{PCa}$ risk. Analyses were adjusted for age, family history of $\mathrm{PCa}$ and ethnicity. Stratified analyses were conducted by $\mathrm{PCa}$ aggressiveness according to the Gleason score. Seeking for relevant interaction between smoking status and BMI trajectories and given that smoking is a major risk factor for many types of cancer, known to decrease obesity, we performed stratified analyses according to smoking status.

Results Overall, 28.6\% were never smokers, $54.9 \%$ former smokers, and $16.5 \%$ current smokers, similarly distributed between cases and controls $(\mathrm{p}=0.21)$. Among never smokers, we observed a slight but not significant increased risk of overall PCa for men with a BMI above $25 \mathrm{~kg} / \mathrm{m}^{2}$; (OR 1.52 [0.97-2.38]) as well as for men with a WC greater to $94 \mathrm{~cm}$ (OR $1.42[0.93-2.16])$ or a WHR greater or equal to 0.95 (OR 1.40 [0.92-2.13]). Among current smokers, we observed no association between BMI, WC or WHR and PCa risk (OR 1.15 [0.62-2.13], OR 1.24 [0.68-2.30], OR 1.06 [0.58-1.93], respectively). However interaction was not significant.

Conclusion Our results showed that associations between anthropometric indicators were more pronounced among never smokers, in agreement with the assumption that smoking may attenuate the association between obesity and cancer.

\section{P32 THE IVEBERG-EFFECT OF SPECIFIC MATERNAL MORBIDITIES IN IRELAND: QUANTIFYING THEIR MAGNITUDE}

S Leitao*, P Corcoran, E Manning. National Perinatal Epidemiology Centre, University College Cork, Cork, Ireland

10.1136/jech-2019-SSMabstracts. 183

Background Death is the last point on the spectrum of adverse pregnancy events. Nevertheless, it is essential to know the full extent to which women's health is affected during or shortly after pregnancy, and to identify their main causes of illness. In developed countries, most maternal deaths are currently avoidable and severe maternal morbidities (SMMs) have been recognised as important indicators of the broader issues affecting maternal health. Therefore, this study aims to quantify the magnitude of specific maternal morbidities in Ireland. Methods The frequency of specific maternal mortalities and morbidities was obtained from: Maternal Death Enquiry
(MDE), Hospital In-Patient Enquiry Scheme (HIPE), NPEC National Audit of SMM, and Growing Up in Ireland. The incidence, crude mortality and case-fatality ratios were calculated for each main maternal condition between 2009 and 2017 (i.e. Haemorrhage, Hypertension, Thromboembolism/ Venous thromboembolism (VTE) and Sepsis).

The iceberg-effect metaphor was used representing the different epidemiologic levels of the various maternal health conditions studied. At the bottom, a healthy pregnancy, topped by manageable maternity complications, followed by severe maternal morbidities and at the peak, maternal mortality.

As the major morbidity affecting women following pregnancy in Ireland, the incidence rate (per 1000 maternities) of Major Obstetric Haemorrhage $(\mathrm{MOH})$ was calculated. Poisson regression was calculated to obtain rate ratios studying the trend of this morbidity throughout the years.

Results Currently, there are more maternal morbidities $(n=619881)$ than maternities in Ireland $(n=604510)$, an event noticed from 2012 onwards.

At the 'tip of the iceberg', thromboembolism (TE) recorded the highest mortality ratio ( 0.23 among 22 maternal fatalities) followed by $\mathrm{MOH}$ (mortality ratio=0.18).

Among the SMMs studied, the case fatality ratio for eclampsia is 25 and for pulmonary embolism this is 26 , highest values recorded.

$\mathrm{MOH}$ remains the SMM with highest incidence in Ireland (crude rate 28.85). The incidence of $\mathrm{MOH}$ increased from 2.34 per 1,000 maternities in 2011 to 3.14 in 2017, an increase of $45 \%$ (rate ratio $=1.45,95 \% \mathrm{CI}=1.18-1.77, \mathrm{p}$ value $<0.001)$.

Sepsis with a case-fatality ratio of 122 recorded the highest value among the group of (non-severe) morbidities studied, as one in 122 cases of this condition might result in death.

Conclusion Although $\mathrm{TE}$ and $\mathrm{MOH}$ were the main causes of maternal death, pulmonary embolism, eclampsia and sepsis emerged as important issues affecting maternal health.

The study of such issues offers the possibility of carrying preventive actions, prioritise and implement timely intervention to tackle critical pregnancy and maternal health issues. Valuable lessons can be learned about the requirements, care and interventions necessary to ensure a better and more efficient response to the specific needs of these women.

\section{P33 MEASURING THE IMPACT OF THE GOVAN SOCIAL AND HEALTH INTEGRATION PARTNERSHIP (SHIP) PROJECT ON EMERGENCY ADMISSIONS TO HOSPITAL AND GP INTERACTIONS: A CONTROLLED INTERRUPTED TIME SERIES ANALYSIS}

${ }^{1}$ KA Levin* , 'E Crighton, ${ }^{2} \mathrm{~V}$ McGarry. ${ }^{1}$ Public Health Directorate, NHS GGC, Glasgow, UK; ${ }^{2}$ Glasgow City Health and Social Care Partnership, Glasgow, UK

\subsection{6/jech-2019-SSMabstracts. 184}

Background The Govan SHIP project was implemented in Govan Health Centre, a deprived area in the south of Glasgow, involving GPs and social workers sitting within multidisciplinary teams to identify and support vulnerable patients at risk of attending A\&E and GP surgeries. This study aimed to measure the impact of SHIP on A\&E presentations and GP interactions.

Methods Rate of A\&E presentations per 1000 population in 3 participating GP practices in Glasgow City was compared 